\title{
Research on the Simulation Processing of the Rake Face of the Ball End Mill
}

\author{
Shuai $\mathrm{Li}^{1, \mathrm{a}}$ and Yuanyuan $\mathrm{Cai}^{2, \mathrm{~b}}$ \\ ${ }^{1}$ College of Mechanical \& Electrical Engineering, Zaozhuang University Shandong province, \\ 277160; \\ ${ }^{2}$ Zaozhuang Experimental School, Shandong province, 277160; \\ alishuai66@163.com. byuanyuancai214@126.com
}

Keywords: Ball end mill; Cutter grinding simulation; Solidworks; Visual basic; Rake face

\begin{abstract}
The ball end mill, as an important tool to process the complex three-dimensional curved surface, is helpful to achieve high efficiency and high precision machining when was used with nc machine tool, which is highly demanded in the manufacturing factory. This paper further analyze the processing theory and method of the ball end mill, and establishes a grinding simulation system of the rake face on the Solid Works platform based on Visual Basic as the secondary development tool; Verifies the validity of the theory though analyzing the simulation results and provides a basis for optimizing the grinding parameters in the practical processing process.
\end{abstract}

\section{Introduction}

The development of numerical control machine tool and mold industry raises a higher requirement for the performance and reliability of the ball end mill. Cutter grinding is critical in the manufacturing process of the ball end mill, whose spiral groove was formed by high-rate grinding of the grinding wheel, but that was processed by multi-axis linkage grinding machine with more adjust parameters, more complex operation and higher cost in our country[1]. Therefore, it's significant for the manufacturer and users of the ball end mill to further optimize the grinding parameters in the manufacture process through the analysis of the mathematical model of the ball end mill.

\section{Grinding Movement of the Rake Face of the Ball Blade}

To implement the cutter grinding of the ball end mill, grinding wheel and the ball end mill have to realize translational movement toward three directions, $\mathrm{X}, \mathrm{Y}, \mathrm{Z}$, and rotate around the axis of the ball end mill. $\sigma=[O ; X, Y, Z] 、 \sigma_{0}=\left[O_{0} ; X_{0}, Y_{0}, Z_{0}\right] 、 \sigma_{S}=\left[O_{S} ; X_{S}, Y_{S}, Z_{S}\right]$ respectively indicate the coordinate system of the ball end mill, machine tool and grinding wheel. For a convenient calculation, we assume that the initial position of the coordinate system of machine tool $\sigma_{0}=\left[O_{0} ; X_{0}, Y_{0}, Z_{0}\right]$ is overlapped with that of work piece, $\sigma=[O ; X, Y, Z]$ and the coordinate origin is in the position $\mathrm{O}$, the center of the ball head. The posture of grinding wheel and the spatial relationship of the ball end mill in the grinding process of the rake face of the ball end mill are shown in Fig. 1. 


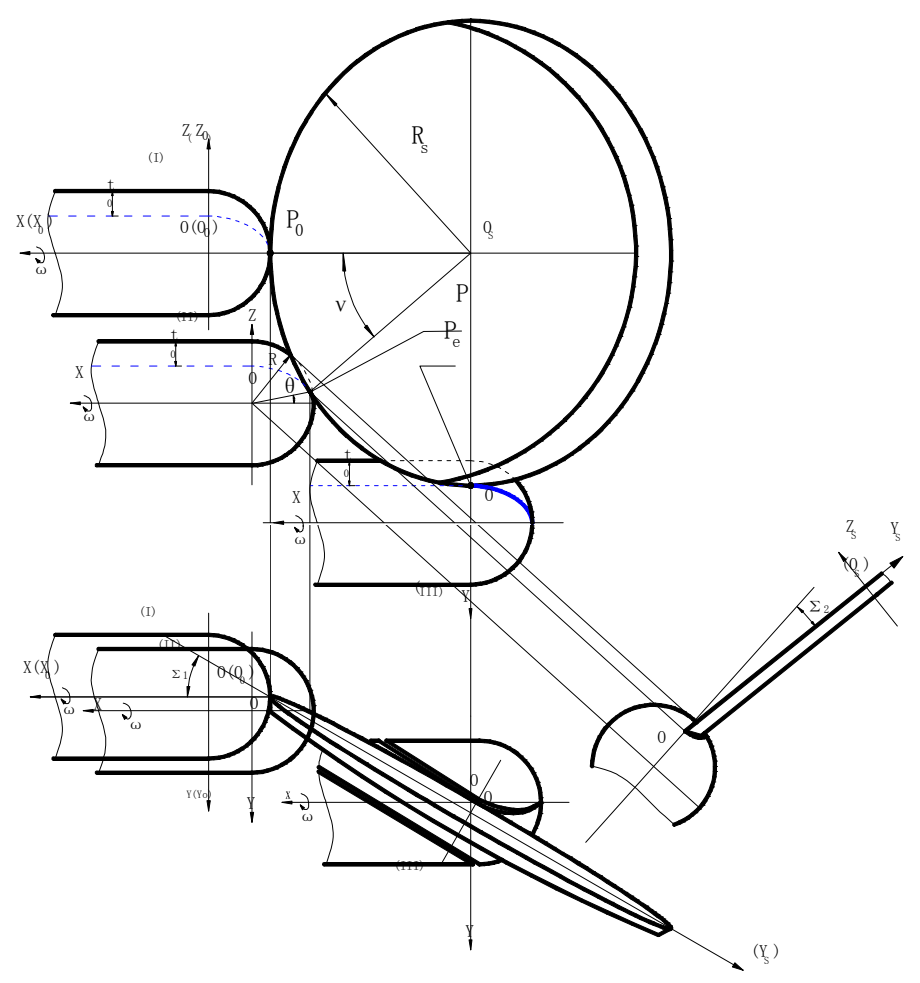

Figure 1. the motion relationship of the rake face of the ball end mill [2]

$\mathrm{BBe}$, as the bottom curve of the rake face of the ball end mill, is always tangent with PoPPe, the large-end circumference of the grinding wheel in the manufacturing process, forming the spiral groove of the rake face[3-4]. In the grinding process of the rake face, the large-end circumference of the grinding wheel is tangent with point $\mathrm{B}$ on the bottom curve first, then $\mathrm{Pe}$, the lowest point on the grinding wheel is tangent with $\mathrm{Be}$, the end of the bottom curve. In order to avoid the interference and over-tangency between the grinding wheel and the spiral groove of the ball end mill, installation Angle $\Sigma 1$ should be $2^{\circ}$ larger than the spiral Angle, and taking spiral Angle as $\beta$, so $\Sigma \beta+1=2^{\circ}$. The circumference surface of the grinding wheel rotates around the horizontal axis of large circle $\Sigma 2$ angles is beneficial to make this grinding method more general and common in usage[5].

The equation of the tangent point $\mathrm{P}$ between PoPPe, the main aspect circumference and $\mathrm{BBe}$, the bottom curve of the ball end mill is:

$$
\left\{\begin{array}{l}
\frac{\mathrm{R}_{\mathrm{S}}(\cos a \cos u-\sin a \cos b \sin u)}{(R-c)^{2} \sin \theta \cos \theta}-\frac{\mathrm{R}_{\mathrm{S}}(\sin a \cos u+\cos a \cos b \sin u)}{(R-c) R \sin ^{2} \theta \cos \omega}=0 \\
\frac{\mathrm{R}_{\mathrm{S}} \sin b \sin u}{(R-c) R \sin ^{2} \theta \sin \omega}-\frac{\mathrm{R}_{\mathrm{S}}(\sin a \cos u+\cos a \cos b \sin u)}{(R-c) R \sin ^{2} \theta \cos \omega}=0
\end{array}\right.
$$

When $\theta$ takes a fixed value, it always corresponded with a set of $\omega$ and $v$ in the equation set Eq.1. According to a series of calculated tangent point $\mathrm{P}$, the tangent point was converted at the bottom curve in $\sigma_{0}=\left[O_{0} ; X_{0}, Y_{0}, Z_{0}\right]$ and the large-end circumference of the grinding wheel, so as to get 
the following formula of the motion curve of the ball end mill and the grinding wheel in the manufacturing process:

$$
\left(\begin{array}{c}
\Delta X \\
\Delta Y \\
\Delta Z
\end{array}\right)=\left(\begin{array}{c}
X_{C_{0}} \\
Y_{C_{0}} \\
Z_{C_{0}}
\end{array}\right)-\left(\begin{array}{c}
X_{S 0} \\
Y_{S 0} \\
Z_{S 0}
\end{array}\right)=\left(\begin{array}{c}
R(1-\cos \theta)+R_{S} \cos a(1-\cos u) \\
R_{S}(\sin v-\sin a)-(R-c) \sin \theta \sin \omega \\
(R-c) \sin \theta \cos \omega+R_{S} \sin a \cos u
\end{array}\right)
$$

\section{Grinding Movement of Rake face of the Circumference Blade}

The forming of the rake face of the circumference Blade is same with the forming principle of the spiral groove on the drill[6], and the relative movement relationship and position relationship between the grinding wheel and the ball end mill in processing are shown in Fig. 2.

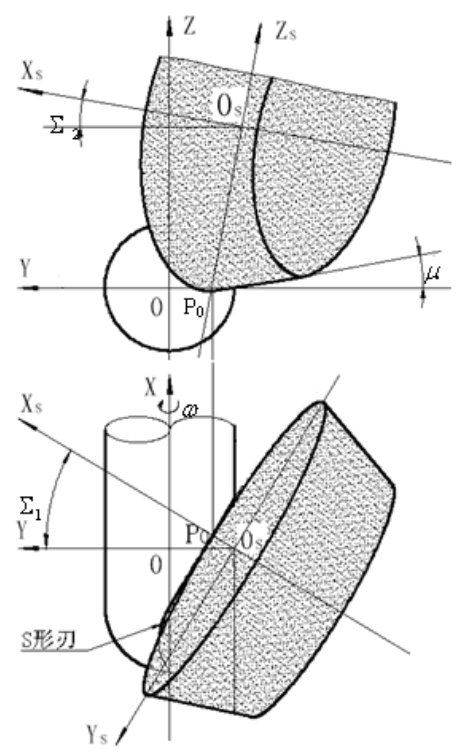

Figure 2. the position relationship between the grinding wheel and the ball end mill

If the rake face of circumference blade is orthogonal helical surface, then its equation can be represented as:

$$
\left\{\begin{array}{l}
X=R_{x} \cos \omega \\
Y=R_{x} \sin \omega \\
Z=\frac{P_{z}}{2 \pi} \omega
\end{array}\right.
$$

In this type: RX is the radius of any point on the rake face of circumference blade, so its calculation formula is: $R_{x}=\sqrt{X^{2}+(X-R)^{2} \tan ^{2} \mu}, \mu_{\text {is the included angle between the generatrix }}$ and axis of the grinding wheel, which is the half taper of the grinding wheel of the circular cone [7]. 


\section{Establishment of Simulation Machining System Based on the Solidworks Platform}

For the purpose of verifying the correctness of the mathematical model and processing movement, a lot of different sizes of the ball end mill blank, and different types and sizes of grinding wheel are needed for trial cutting, and for the convenient measurement of the related parameters and avoiding the waste of materials, a set of grinding simulation and machining system of the rake face was founded on the SolidWorks platform with Visual Basic language as the secondary development tools[8-9]. First of all, begin with parametric design for the ball end mill and grinding wheel, that means opening the macro recording to create physical model in SolidWorks with the parameter size marked by variables, so macro recording gets entity established code base, then parameterized modeling of the ball end mill blank and grinding wheel could be realized in the way of controlling the variables on the bases of the objects and methods of macro file organized reasonably, modified a little and variables used to replace the specific parameters [10] in its own application. After that, the rake face was formed by means of Boolean difference calculation between the entities to make the grinding wheel to realize the simulated grinding process for the milling blank after using the milling blank entity generated by parametric modeling and the grinding wheel entity, the simulation results are shown in Fig. 3.

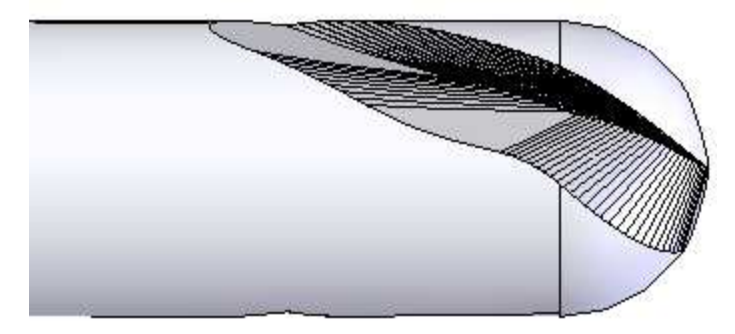

Figure 3. the grinding simulation processing results of the rake face

\section{Conclusion}

Machining simulation system can simulate the grinding process of the rake face of the ball end mill better, and the motion relationship proposed in the early stage can continuous grind the rake face of the ball blade and circumference blade, which verifies the validity of the mathematical model; the rake face of the ball blade continuous transit with that of circumference blade, and the blade curve of the ball is s-shaped; the distribution of the rake face of ball blade in distributed in a reasonable way with a maximum as $32^{\circ}$.

\section{References}

[1] He Lin, Lishuai, etc. Grinding simulation of the Rake Face of the Ball End Mill. Journal of mechanical design and manufacturing, 2009 (2): $250 \sim 251$.

[2] Li Shuai.Modeling and Simulation Research of Ball End Mill Rake Face. Chemical Engineering Transactions.Vol.51,2016:1237-1241.

[3] Lishuai. The Secondary Development and Parametric Design of SolidWorks. Journal of Zaozhuang College, 2010 (2) : $79 \sim 82$.

[4] SolidWorks Corporation. SolidWorks API help 2005. 2015.

[5] Xia Wensheng, et al. Effects of wheel wear on the manufacturing errors of ball-nose end milling cutter. Modular Machine Tool and Automatic Manufacturing Technique. 2013(1):39-41. 
[6] Zhu Mengzhou. Mechanical Engineers Handbook (second edition). Mechanical industry publishing house, 2000.

[7] Sun Liming. Error Compensation and Study on the Rake Face of the Ball End Mill in the Grinding Simulation Processing. Master thesis of guizhou university, 2009, 6.

[8] Ren Bingyin, Tang Yuyong. The Geometric Modeling Theory and Its Application in the Nc Machining. Journal of Harbin Industrial University press, 2000, 1.

[9] Hebiao. Research on the Grinding Processing of the New type of Ball End Mill. Master thesis of Guizhou University, 2005, 6.

[10]Li Guochao, Sun Jie.Current Research and Development Trends of End Mill Grinding Simulation Technology. Journal of Mechanical Engineering.Vol.51,No.9,2015.5:165-175. 